\title{
Body Composition and Associations with Muscle Strength in Older Adults Living in Auckland, New Zealand ${ }^{\dagger}$
}

\author{
Anne N. Hiol, Pamela R. von Hurst, Cathryn A. Conlon and Kathryn L. Beck* \\ School of Sport, Exercise and Nutrition, Massey University, North Shore City 0632, New Zealand; \\ AnneNadine.Hiol.1@uni.massey.ac.nz (A.N.H.); p.r.vonhurst@massey.ac.nz (P.R.v.H.); \\ c.conlon@massey.ac.nz (C.A.C.) \\ * Correspondence: k.1.beck@massey.ac.nz.; Tel.: +64-9-414-0800 (ext. 43662) \\ + Presented at the 2019 Annual Meeting of the Nutrition Society of New Zealand, Napier, New Zealand, \\ 28-29 November 2019.
}

Published: 17 March 2020

Objectives: To investigate associations between body composition and muscle strength in older adults living in New Zealand.

Design: Adults aged 65-74 years living independently were recruited from the cross-sectional Researching Eating Activity and Cognitive Health (REACH) study. Body fat percentage and Appendicular Muscle Mass (ASM) (sum of lean mass in the arms and legs) were measured using Dual-energy X-ray Absorptiometry (DXA; Hologic, Discovery QDR series). The ASM index was calculated by ASM (kilogram) divided by height (meters) squared. Maximum grip strength was measured on the dominant hand using a hand-grip dynamometer (JAMAR HAND).

Results: Participants $(n=369)$ were $69.7 \pm 2.6($ mean \pm SD) years and $64 \%(n=236)$ female. Mean body fat percentage was $36.1 \pm 5.3 \%$ for women, and $24.5 \pm 4.4 \%$ for men. The ASM index for women was $6.85 \pm 1.1 \mathrm{~kg} / \mathrm{m}^{2}$ and for men $8.89 \pm 1.0 \mathrm{~kg} / \mathrm{m}^{2}$. Low muscle mass $\left(<5.5 \mathrm{~kg} / \mathrm{m}^{2}\right.$ for women and $<7$ $\mathrm{kg} / \mathrm{m}^{2}$ for men) was observed in $6.3 \%$ of women and $2.3 \%$ of men. Mean grip strength was $24.7 \pm 4.6$ $\mathrm{kg}$ (women) and $41.0 \pm 7.7 \mathrm{~kg}$ (men). Low muscle strength ( $<16 \mathrm{~kg}$ for women and $<27 \mathrm{~kg}$ for men) was observed in $4.6 \%$ of women and $1.5 \%$ of men using the Revised European Working Group on Sarcopenia in Older People definition. Linear regression analyses revealed that lower muscle strength was associated with higher body fat percentage (model $\mathrm{R}^{2}=0.436, p<0.001$ ) and lower muscle mass (model R ${ }^{2}=0.431, p<0.001$ ).

Conclusions: High body fat percentage and low muscle mass were associated with low muscle strength in this cohort. However, further investigations are necessary to determine the causal relationship of body composition and muscle strength.

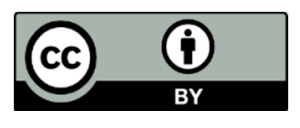

(C) 2020 by the authors. Licensee MDPI, Basel, Switzerland. This article is an open access article distributed under the terms and conditions of the Creative Commons Attribution (CC BY) license (http://creativecommons.org/licenses/by/4.0/). 